\title{
Hermenêutica ontológica aplicada à semiologia médica: por que os discentes de Medicina devem estudar Heidegger
}

\author{
Hermeneutic ontology applied to medical semiology: why medical students should read Heidegger
}

João Pedro Paz Takeuchi' (D) |joaopedropaztakeuchi@gmail.com

\section{RESUMO}

Introdução: Devido à complexidade da atual abordagem médica, várias áreas temáticas que não lhe são específicas devem ser de seu entendimento, como a hermenêutica. Durante os últimos séculos, essa linha filosófica participou de diversas mudanças de paradigmas, os quais só puderam ser de fato superados a partir do século XX, principalmente com a obra Ser e tempo, de Martin Heidegger.

Desenvolvimento: Foi realizado um ensaio acerca de algumas implicações da obra Ser e tempo para as práticas de ensino-aprendizagem semiológica. Nota-se que o entendimento fenomenológico pode contribuir para ensino-aprendizagem para além dos domínios cognitivos ao abordar: o que é semiologia, o que é a fala, como a antropologia interage com a medicina, o que é "empatia" e de como lidar com a "morte". Destaca-se o potencial dessa abordagem para o fornecimento de perspectivas propriamente mais humanas, o que, na prática médica, deve ser transmitido nas atividades de ensino-aprendizagem.

Conclusão: Apesar de não prover resoluções, tal discussão aponta o campo da hermenêutica fenomenológica como de possível interesse para o desenvolvimento profissional.

Palavras-chave: Educação Médica; Hermenêutica; Pesquisa Interdisciplinar; Filosofia Médica.

\begin{abstract}
Introduction: Due to the complexity of the current medical approach, several topics from different fields should be considered as part of its understanding, such as hermeneutics. This philosophical branch has contributed to several paradigm shifts in the last few centuries, but such paradigms could only be truly overcome from the 20th century onwards, especially since Martin Heidegger's work, Being and Time.

Development: This purpose of this essay was to relate some implications of Being and Time to medical semiology, one of the cornerstones of the medical activity. Exploring briefly some basic themes of medical practice in light of hermeneutic phenomenology, it is possible to identify contributions it has made to the training of health professionals beyond technical parameters, by asking questions such as: what is Semiology? What is talking? How do Anthropology and Medicine interact? What is "empathy" and how should we deal with "death"? It is necessary to highlight the importance of this approach to provide greater human understanding about medical practices.
\end{abstract}

Conclusion: Although this discussion does not provide definitive solutions, it shows how hermeneutic phenomenology is a field of potential interest to medical training.

Keywords: Medical Education; Hermeneutics; Interdisciplinary Communication; Medical Philosophy.

${ }^{1}$ Faculdade de Ciências Médicas de Minas Gerais, Belo Horizonte, Minas Gerais, Brasil.

Editora-chefe: Daniela Chiesa

Editora associada: Daniela Chiesa

Recebido em 14/07/20; Aceito em 24/11/20.

Avaliado pelo processo de double blind review. 


\section{INTRODUÇÃO}

Tomando como partida a atividade médica para algo além da mera dicotomia saúde-doença ${ }^{1}$, é essencial à formação acadêmica o entendimento de diversas áreas de conhecimento, inclusive a hermenêutica moderna e contemporânea.

Ao rejeitarem ideais românticos e iluministas, alguns intelectuais do final do século XVIII direcionam o pensamento ocidental contra a dita "história universal" das civilizações de base hegeliana, contra a razão crítica de Kant e em prol da relativização do entendimento do mundo ${ }^{2}$. Essas ideias se aproximam daquelas classicamente relacionadas à "medicina

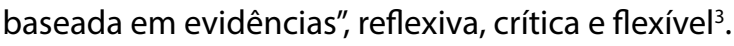

Entretanto, fica claro que esses e outros autores não foram capazes de superar as restrições e falácias intelectuais que apontavam, muitas vezes, na verdade, reproduzindo-as sem perceberem. Houve apenas uma substituição do "ideal" para o "relativo", sem a devida exploração de questões anteriores (originárias) como a do próprio ser ${ }^{4}$. Ainda de maneira análoga, não se visa aqui rejeitar as práticas ditas baseadas em evidências, mas sim questionar elementos ainda mais originários a ela. Logo, não se espera trazer benefícios (ao menos diretamente), diagnósticos e terapêuticos, nem auxiliar na tomada de decisões; na verdade, pretende-se instigar compreensão, interpretação, reflexão e flexão sobre o cotidiano da profissão.

Cronologicamente, esse fenômeno intelectual torna-se mais perceptível já na obra de Friedrich Nietzsche ${ }^{5}$ e assume sua conformação primeira formal mais complexa na obra de Martin Heidegger, especialmente em Ser e tempo ${ }^{6}$.

Deve-se ressaltar que, para aplicação de algo sobre outro, é necessário apreender este primeiro. Assim, não se pode e nem se pretende abranger a complexidade do pensamento heideggeriano com esse texto (ou mesmo somente com os textos do autor original). Como a medicina, uma corrente positiva, necessariamente se baseia nos preceitos da comunidade científica e a rejeição dos pensadores mais tradicionalmente aceitos cria um vácuo teórico, optou-se por estudar possíveis interfaces da hermenêutica ontológica heideggeriana com a prática médica, especialmente o seu início, já que pode ser considerado um ponto sensível.

Assim, este ensaio buscou alinhar alguns enfrentamentos apontados pela literatura durante a iniciação à semiologia médica (um dos primeiros momentos de contato dos discentes com a medicina e, portanto, um ponto vulnerável da formação), especialmente aqueles referentes aos pacientes e aos próprios acadêmicos ${ }^{7}$, com conhecimentos da hermenêutica heideggeriana apresentados em Ser e tempo.

Dadas a extensão e complexidade da temática e as deficiências tanto da literatura especializada quanto dos cursos de graduação para compreensão e integração dos estudos de humanidades na Medicina, não se espera que esta breve discussão seja suficiente para impactar de fato a educação médica no Brasil. Entretanto, crê-se possível instigar educadores e educandos a explorar esse campo de conhecimento e propor investigações mais apropriadas e aplicadas a suas realidades.

\section{DESENVOLVIMENTO}

Uma das primeiras aprendizagens possibilitadas pela hermenêutica (aqui não necessariamente a heideggeriana) diz respeito a seu método. Quando se analisa a linguagem em seu sentido mais originário, podem-se apreender acepções perdidas com o uso vulgar cotidiano.

Inicialmente, deve-se compreender o que é "semiologia". Partindo-se, de maneira rasa, da definição de Saussure, temse a ciência geral dos signos, a semiose; esta tem duas ideias fundamentais: a semiologia e o tripé de definição de uma unidade sonora. A semiologia designa a constituição negativa dos fonemas, ou seja, todas as maneiras de linguagem que criam sentido até então inexistentes, e o tripé se faz a partir dessa arquitetura semiológica, do enunciador e do enunciatário. Assim, a semiologia nasce necessariamente com valor intrinsecamente epistemológico ${ }^{8}$.

Nas disciplinas de semiologia médica, um dos destaques é o desenvolvimento da capacidade de realizar anamneses, que instrumentalmente se vale da fala. Entretanto, pelo menos inicialmente, é perceptível a dificuldade de exercer a habilidade corretamente 9 . Primeiramente, é preciso entender a função da fala; "deixar e fazer ver", ou seja, descobrir algo oculto. Por sua vez, a prática da fala ocorre entre indivíduos que existem num mundo e apenas assim pode ser verdadeira (ou seja, de poder descobrir) ${ }^{10}$; logo, elementos mecanicistas, como entrevistas estruturadas, não facilitam de fato a fala, apenas mascaram sua ineficácia.

Com a fala devidamente executada, apreendemos algo então descoberto. Esse algo descoberto não é um elemento por si só que simplesmente está lá (ser simplesmente dado), mas tem um valor ${ }^{11}$, significado clínico. Entretanto, é preciso extrapolar essa noção; no conceito mais originário grego de "coisas", tem-se "aquilo que se lida de maneira pragmática em uma 'ocupação' no 'mundo'”; isso na prática médica seria equivalente à mera correspondência de certo sinal patognomônico a alguma entidade nosológica. Essa visão do objeto de estudo como um mero instrumento", "um simples caso a ocupar um leito numerado"13 é, no mínimo, eticamente questionável.

Ainda explorando esse aspecto, deve-se refletir sobre as práticas denominadas "centradas na pessoa", "holísticas", "antropológicas" e "humanistas". Essas correntes levantam a questão da complexidade biopsicossocial, levando a medicina para além da mera biologia positivista; indo da "cura" de 
moléstias para a promoção de saúde ${ }^{14}$. Mas essas práticas também não são, ou pelo menos não deveriam ser, simples interseções de diversas áreas do conhecimento cotidiano ou atuação "junto a" outros campos de atuação; já que, ao existir verdadeiramente (ou seja, de forma a descobrir), existe-se num mundo com outros seres. Portanto, compreender e interpretar o paciente não é uma simples questão de acionar outros setores do sistema de saúde e sim uma exploração da existência do outro ${ }^{15}$.

Essa questão, por sua vez, ultrapassa os limites da "empatia" em suas acepções vulgares. Deve-se ter a empatia como uma consequência, e não como uma origem do ser-com o outro e muito menos um originário. Ou seja, a empatia não é um fenômeno metafísico e/ou subjetivo, mas um aspecto real da existência de fato do ser, na medida em que este é sempre ser-com-outro, em convivência ${ }^{15}$.

Por conseguinte, na aprendizagem, entendendo o princípio da fala, o estudante passa pela ansiedade de construir o pensamento clínico adequado ${ }^{7}$. Nesse processo, percebe-se a necessidade de interação com o mundo circundante, que está aberto mas inacessível ao estudante ${ }^{16}$, ou seja, não tem real compreensão da pertinência dos instrumentos descobertos. Entretanto, deve-se apreender na noção temporal desse fenômeno de aprendizagem, ainda que não necessariamente progressiva e/ou linear, pois o desenvolvimento do pensamento clínico é necessariamente algo condicionado ao tempo (historicidade). Assim,

O modo de lidar, talhado segundo o instrumento, $e$ único lugar em que ele se pode mostrar genuinamente em seu ser como, por exemplo, o martelar o martelo, não apreende tematicamente esse ente como uma coisa que apenas ocorre, da mesma maneira que o uso não sabe da estrutura do instrumento como tal ${ }^{16}$.

À medida que se amadurece o pensamento clínico, tem-se o aumento do aporte teórico que a medicina, como ciência, oferta. Assim, é de suma importância o entendimento da própria ciência, nesse caso como um instrumento e em suas manifestações à mão (manuais). Partir dos debates sobre "ciência" do século XX, especialmente nas figuras de Popper e Kuhn, a ciências é considerada de maneira mais homogênea entre os pensadores como necessariamente dependente de observadores, mesmo em práticas não estritamente observacionais ${ }^{17}$ (como inclusive pode-se ver na fundamentação anterior do que é a semiologia médica). Logo, a prova observacional não pode aceitar como verdadeiro (aqui com o sentido de correspondente à realidade sensível) aquilo que justamente busca fundamentar. Entretanto, a interpretação de novos dados científicos, sendo posterior à compreensão e, portanto, à fala, já está "contaminada" por elementos que não são originários, o que necessariamente estrutura as ciências positivas mecanicamente dependentes de circulus vitiosus ${ }^{18}$ ). Isso implica que, na busca pelos saberes da medicina, deve-se ser criticamente ativo.

Um outro processo que os estudantes de Medicina sofrem envolve a "experiência" da morte. Morte dá-se aqui num sentido amplo, para além do que se compreende propriamente como morte biológica; a extensão originária em questão envolve também necessariamente a compreensão de que a prática profissional muitas vezes tende mais ao paliativismo do que à cura terapêutica ${ }^{13}$. Entretanto, é preciso afastar dessa discussão o luto abordado pelas linhas psicológicas, assim não se tratando de diversos modos do ser diante da morte clinicamente passíveis de categorização; tem-se na verdade a angústia, e, assim, o ser humano e os animais são, mas apenas o primeiro existe de fato, só ele tem o enfrentamento da finitude existencial ainda que isso em si não gere algo negativo ou traga pavor ou "angústia" nos sentidos usuais quanto a sentimentos (disposições) desagradáveis, mas permite a abertura para abraçar as múltiplas possibilidades da existência ${ }^{19}$.

Isso decorre de dois outros fenômenos: 1. não "vivemos a morte de outro", como se diz vulgarmente; e 2. de fato, não temos a certeza da morte, então fugimos dela. Quando se explora a primeira afirmação, nota-se que o deixar de viver do outro não nos traz de fato a vivência sua de morte, apenas nos permite constatar que este não está mais acessível. Com essa constatação temos então, a partir do "saber cotidiano", que a morte apenas é constatável empiricamente, já que ninguém que não deixou de estar vivo relata experienciar a morte. $\mathrm{O}$ que leva à segunda afirmação, ou seja, não temos certeza da morte e dizemos que "com certeza se morre, mas hoje não". Nessa fuga da morte, negamos também a angústia, negamos as possibilidades do ser, e nos alienamos ${ }^{20}$. Temos, por fim, que a medicina nos traz a chance de abertura do ser, mas que podemos nos sabotar.

O eterno devir desses e de outros fenômenos anterior e brevemente explorados perpassa necessariamente a questão do tempo. Aqui não se deve ater à concepção vulgar de "tempo" como equivalente a uma medida física (mensurável) que comporta infinitos agoras, mas sim como historicidade ${ }^{21}$. Quanto ao processo de negar a tradição e abraçar o passado (o processo eterno do ser-no-mundo), na arte da medicina, como na Arte, entram ambos os agrupamentos em ressonância e com os que criam e os que descobrem, como um ser-aí do seu povo ${ }^{22}$.

\section{CONCLUSÃO}

É necessário reforçar que não se pretendeu explorar essa discussão em sua totalidade. Ainda assim, é possível concluir que o pensamento hermenêutico ontológico pode contribuir para mitigar as ansiedades dos alunos que adentram nos primórdios 
da prática clínica e questionam suas habilidades, competências e como estas relacionam-se com o mundo e seus seres; nesse caso, especialmente os pacientes e os médicos que serão.

São necessárias mais investigações com mais poder científico nesse campo, tanto de cunho teórico para aprofundar os itens brevemente explorados (e outros nem mencionados) quanto de caráter prático para aproximar os iniciados na prática médica com reflexões e ações mais humanas.

\section{CONFLITO DE INTERESSES}

Declaro não haver conflito de interesses.

\section{FINANCIAMENTO}

Declaro não haver financiamento.

\section{REFERÊNCIAS}

1. Larson JN. The measurement of health: concepts and indicators. New York: Greenwood Publishing Group; 1991.

2. Bentivoglio J. História e hermenêutica: a compreensão como um fundamento do método histórico - percursos em Droysen, Dilthey, Langlois e Seignobos. Opsis. 2010;7(9):67-70 [acesso em 18 jan 2020]. Disponível em: https://www.revistas.ufg.br/Opsis/article/view/9329.

3. Haynes RB, Sackett DL, Richardson WS, Rosenberg W, Langley GR. Evidence-based medicine: how to practice \& teach EBM. Can Med Assoc J. 1997;312(7023):71-2.

4. Heidegger M. Ser e tempo. Bragança Paulista: Editora Universitária São Francisco; 2018.

5. Tavares $\mathrm{O} . \mathrm{O}$ confronto radical entre Nietzsche e Heidegger em relação à superação da metafísica. Controvérsia. 2012;8(3):12-32 [acesso em 19 jan 2020]. Disponível em http://revistas.unisinos.br/index.php/controversia/ article/view/6937/3880.

6. Schuback MSC. A perplexidade da presença. In: Heidegger M. Ser e tempo. Bragança Paulista: Editora Universitária São Francisco; 2018. p. 15-33.

7. Costa GPO, Herculano TB, Gama ALH, Cabral RP et al. Enfrentamentos do estudante na iniciação da semiologia médica. Rev Bras Educ Med. 2018;42(2):79-88.

8. Beividas W. A semiologia de Saussure como epistemologia do conhecimento. Revista em Estudos em Linguísticas. 2016;24(1):35-64 [acesso em 18 jan 2020]. Disponível em: http://www.periodicos.letras. ufmg.br/index.php/relin/article/view/6959.
9. Dorigatti $A E$, Faber EW, Garcia Junior C, Turato ER. Como se sentem pacientes quando examinados por estudantes de Medicina? Um misto entre ambiguidades e satisfações encontradas em estudo qualitativo. Rev Bras Educ Med. 2015; 39(1):95-101 [acesso em 18 jan 2020]. Disponível em: $\quad$ http://www.scielo.br/scielo.php?script=sci_arttext\&pid=S0100$55022015000100095 \&$ lng $=e n \& n r m=$ iso.

10. Heidegger M. O conceito de logos. In: Heidegger M. Ser e tempo. Bragança Paulista: Editora Universitária São Francisco; 2018. p. 71-3.

11. Heidegger M. Caracterização prévia do ser-no-mundo a partir do serem como tal. In: Heidegger M. Ser e tempo. Bragança Paulista: Editora Universitária São Francisco; 2018. p. 98-105.

12. Heidegger $\mathrm{M}$. $\mathrm{O}$ ser dos entes vêm ao encontro no mundo circundante. In: Heidegger M. Ser e tempo. Bragança Paulista: Editora Universitária São Francisco; 2018. p. 114-25.

13. Porto CC, Porto AL. Relação médico paciente. In: Semiologia médica. Rio de Janeiro: Guanabara Koogan; 2015. p. 21-37.

14. Méndez OQ, Hechavarría COO, Rivera JM, Moret M, Herrera MYF. Consideraciones antropológicas en el proceso de formación profesional del médico general. Medisan. 2013;17(10):7021-30.

15. Heidegger M. A copresença dos outros e o ser-com cotidiano. In: Heidegger M. Ser e tempo. Bragança Paulista: Editora Universitária São Francisco; 2018. p. 173-82.

16. Heidegger M. A determinação mundana do mundo circundante que se anuncia no ente intramundano. In: Heidegger M. Ser e tempo. Bragança Paulista: Editora Universitária São Francisco; 2018. p. 121-5.

17. Rufatto $C A$, Carneiro, MC. A concepção de ciência de Popper e o ensino de ciências. Ciênc. Educ. (Bauru). 2009;15(2):269-89.

18. Heidegger M. Compreender e interpretação. In: Heidegger M. Ser e tempo. Bragança Paulista: Editora Universitária São Francisco; 2018. p. 209-15.

19. Heidegger M. Prelineamento da estrutura ontológico-existencial da morte. In: Heidegger M. Ser e tempo. Bragança Paulista: Editora Universitária São Francisco; 2018. p. 324-8.

20. Heidegger M. O possível ser-todo da presença e o ser-para-a-morte. In: Heidegger M. Ser e tempo. Bragança Paulista: Editora Universitária São Francisco; 2018. p. 309-44.

21. Heidegger M. A tarefa de uma destruição da história da ontologia. In: Heidegger M. Ser e tempo. Bragança Paulista: Editora Universitária São Francisco; 2018. p. 57-64.

22. Heidegger M. A verdade e obra de arte. In: Heidegger M. A origem da obra de arte. São Paulo: Edições 70. p. 145- 201. 